\title{
The Analysis of Weak-Form Efficiency in the Market of Crude Oil
}

\author{
Anna Górska \\ Warsaw University of Life Sciences, \\ Department of Agricultural Economics and International Economic Relations \\ Monika Krawiec \\ Warsaw University of Life Sciences, \\ Department of Econometrics and Statistics
}

\begin{abstract}
Crude oil is the strategic commodity whose market has become the biggest commodity market in the world over the past 40 years. The main actors in the market, such as producers, refiners, financial institutions, and individual traders are interested in recognizing some trends, patterns or anomalies in performance of oil prices and returns, they could benefit from. Such anomalies among others are calendar effects, for example the dayof-the week effect, the month-of-the year effect, holidays effect or the turn-of-the month effect. Either the calendar effects are observed for stock prices, or for commodity prices, they make the markets inefficient. According to classical Fama's definition: a market in which prices always fully reflect available information is called efficient. However, there are 3 types of market efficiency: weak-form efficiency, semistrong-form efficiency, strong-form efficiency. The weak-form market efficiency is tested the most often. There are several tools used for its verification, for example: some statistical tests (unit root tests, autocorrelation tests, variance ratio tests), long-run relationships and correlation analysis, calendar effects analysis. Our previous research focused on searching for calendar effects in the market of crude oil (Górska, Krawiec 2015), shows the existence of the-day-of-the week and the month effects. It may imply market inefficiency. That is why the present paper is aimed at further testing weak-form market efficiency. The empirical data covers daily closing prices of crude oil in USD per barrel from 2000 to 2015 and includes, both West Texas Intermediate (WTI) and Brent quotations. Having calculated their logarithmic returns, we apply the following tests: runs test, variance ratio, autocorrelation test.
\end{abstract}

Keywords: crude oil, weak-form market efficiency, statistical tests

\section{Introduction}

Oil along with currencies and gold are the main indicators of the most important processes in the world economy. Moreover, oil is the world's dominant fuel with $33 \%$ share in current global primary energy consumption, which is however predicted to decrease to $28 \%$ by 2030 (Popescu 2016). With no doubt, in the last century it has become a highly demanded product, absolutely necessary for the development of every economy.

Since the 1970s macroeconomists have viewed the price of oil as one of the important sources of economic fluctuation, and a driver of global economic shocks. Consequently, oil prices have been carefully followed and analyzed by empirical and theoretical economists. A sufficient understanding of the signals from oil prices is important as both, short-run and long-run decisions are based on information provided by the price of this essential resource, that still remains an important input factor influencing a variety of investment decisions in all economic sectors.

Oil is also the strategic commodity whose market has become the biggest commodity market in the world over the past several decades. The main actors in the market, such as producers, refiners, financial institutions, and individual traders 
are interested in recognizing some trends, patterns or anomalies in performance of oil prices and their returns, they could benefit from. Such anomalies among others are calendar effects, for example the day-of-the week effect, the month-of-the year effect, holidays effect or the turn-of-the month effect. Either the calendar effects are observed for stock prices, or for commodity prices, they make the markets inefficient. Efficient market hypothesis received much attention in the late 1970s and 1980 when a vast amount of literature examined the efficiency of stock markets (see Fama 1970, Fama and French 1988, Lo and MacKinlay 1988, Fama 1991). Efficiency of commodity markets was also studied, although not to the same extent.

According to classical Fama's definition: a market in which prices always fully reflect available information is called efficient. However, there are 3 types of market efficiency: weak-form efficiency, semistrong-form efficiency, strong-form efficiency. The weak-form market efficiency is tested the most often. There are several tools used for its verification, namely some statistical tests, long-run relationships and correlation analysis, calendar effects analysis (including the generalized method of moments, the method of generalized spectrum, mean variance (MV) and stochastic dominance (SD) approaches, detrended fluctuation analysis, time-varying parameter models). However the statistical tests, such as the variance ratio test, the unit root test, the autocorrelation test still remain popular instruments in testing weak-form efficiency of stock markets (see Borges 2010, Aatola, Ollikka and Ollikainen 2010, Guidi, Gupta and Maheshwari 2011, Nisar and Hanif 2012, Khrapko 2013 or Shaker 2013) and sometimes of commodity markets (see Smith 2002, Charles and Darne 2009, Górska and Krawiec 2013, Ntim et.al. 2015).

As our previous research focused on searching for calendar effects in the market of crude oil (Górska, Krawiec 2015) shows the existence of the-day-of-the week and the month effects, it may imply market inefficiency. That is why the present paper is aimed at further testing weak-form market efficiency. The empirical data covers daily closing prices of crude oil in USD per barrel from 2000 to 2015 and includes both, West Texas Intermediate (WTI) and Brent quotations. Having calculated their logarithmic returns, we apply the following tests: runs test, variance ratio test, autocorrelation tests.

\section{Methodology}

The efficient market hypothesis is a concept of informational efficiency, and refers to market's ability to process information into prices. The idea of the efficient market hypothesis $(E M H)$ emerged as early as the beginning of the twentieth century in the theoretical contribution of Bachelier (1900) and the empirical research of Cowles (1933). In the paper of Samuelson (1965) one can find an opinion about price changes and their predictability: If we correctly predict asset prices, their changes should be unpredictable. Correct prediction of prices means taking into account all available information, including information about the expectations of other market participants.

Basic types of information for testing the efficiency of the capital market are:

historical quotes of values,

all publicly available information,

all the information available to market participants (also confidential information).

Analyzing the efficiency of capital market with respect to the above information categories it is necessary to specify three forms of efficiency. These are: weak, semi-strong and strong form of efficiency. However, this is the weak-form that is examined the most often. Fama (1970) defines weak-form efficiency as follows: security prices fully reflect the information contained in past price movements, i.e., they do not follow repeating patterns, and it is impossible to trade profitably purely on the basis of historical price information. The essence of weak-form efficiency is that past returns on a market cannot be utilized to predict current returns on the same market (Haugen 1996).

In order to examine efficiency in the weak form one can use statistical tests that verify the randomness of changes in the time series. They are both parametric and non-parametric tests. The verification may consist in:

assessing whether prices of financial instruments are well described by a random walk process:

$$
p_{t}=p_{t-1}+e_{t}
$$


where $p_{t}$ - logarithms of prices;

assessing whether the returns on investments in financial instruments have property of the white noise:

$$
r_{t}=e_{t}
$$

The aim of the research is to clarify whether the model (1) is a good approximation for the analyzed prices of oil, and whether it can be stated that the model (1), where $e_{t}$ are independent random variables with the same distribution (with finite variance), is a proper model for these prices. Thus, we perform runs test, variance ratio tests, autocorrelation tests, portmanteau and adjusted portmanteau tests.

\section{Runs test.}

Runs test belongs to the group of non-parametric tests also known as compliance tests. Non-parametric tests are used to verify hypotheses about the type of distribution of the variable, and to determine whether samples extracted from the population have the same distributions (Domański and Pruska 2000). A run in the commodity market is defined as a series of changes in commodity prices in the same direction (i.e. a series of increasing values, or a series of decreasing values) of any length (Czekaj and all, 2001). In this case, fractions will be compared to the distribution the data would follow if the investigated process was a random walk. If price changes are random, the probability of a further decline, after the price decreases, should be equal to the probability of an increase. This would mean that in a large sample of observations one should expect similar numbers of runs and sign changes.

Modeling the behavior of commodity prices, one assumes the existence of series of positive values, negative values and zeros. Then, in order to perform the runs test, there is introduced auxiliary variable $R_{t}^{*}$, such that:

$$
R_{t}^{*}=\left\{\begin{array}{ccc}
1, & \text { if } & R_{t}>0 \\
0, & \text { if } & R_{t}=0 \\
-1, & \text { if } & R_{t}<0
\end{array}\right.
$$

The null hypothesis $\mathrm{H}_{0}:$ " $R_{t}^{*}$ is a white noise" is tested against $\mathrm{H}_{1}$ : " $R_{t}^{*}$ is not a white noise".

To verify the hypothesis, $K$ statistic is used. For large samples it is approximately asymptotically normally distributed $(\mathrm{N}(0$, 1)).

Statistic $\mathrm{K}$ is given by:

$$
K=\frac{H-E(\tilde{H})}{\sqrt{\operatorname{War}(\tilde{H})}},
$$

where: $H$ is conditional realization of a random variable $\tilde{H}$ and denotes the total number of runs.

In order to perform this test, continuous sequences of positive, zero and negative returns $R_{t}^{*}$ are first distinguished. There is also introduced an auxiliary variable $h_{t}$ such that:

$$
h_{t}=\left\{\begin{array}{ll}
0, & \text { if } R_{t}^{*}=R_{t+1}^{*} \\
1, & \text { if } R_{t}^{*} \neq R_{t+1}^{*}
\end{array} .\right.
$$

If $h_{t}=1, R_{t+1}$ starts a new run. The total number of runs is: 


$$
H=1+\sum_{t=1}^{n-1} h_{t}
$$

where:

$n$ is the length of a run.

If the investigated series consists of $n_{1}$ positive returns, $n_{2}$ with values of zero and $n_{3}$ negative returns, then the mean and variance of the random variable $\tilde{H}$ are defined by the formulas (Taylor 1986):

$$
\begin{aligned}
& E(\tilde{H})=n+1-\frac{\sum_{j=1}^{3} n_{j}^{2}}{n}, \\
& \operatorname{War}(\tilde{H})=\frac{\sum_{j=1}^{3} n_{j}^{2}\left(\sum_{j=1}^{3} n_{j}^{2}+n+n^{2}\right)-2 n \sum_{j=1}^{3} n_{j}^{3}-n^{2}}{n^{3}-n} .
\end{aligned}
$$

If $|K|>1.96$, then the null hypothesis is rejected at the $5 \%$ level. When $K<0$, we have trends in the data, and $K>0$, implies mean reversion (Taylor 1986).

\section{Variance ratio test}

Performing the variance ratio test, we assume that we have $n k+1$ spot prices (e.g. daily): $S_{0}, S_{1}, \ldots, S_{n k}$.

The variance ratio test is used to verify whether the equation:

$$
p_{t}=\mu+p_{t-1}+e_{t}, \mathrm{t}=1, \ldots, n k
$$

(where $p_{t}=\ln \left(S_{t}\right)$ and $\mu$ - a constant) is a proper model for the analyzed price series (the null hypothesis $\mathrm{H}_{0}$ of this test states that equation (7) is the right model for the series of prices of assets).

The model can be tested in two variants:

$e_{t}$ are independent and follow the same normal distribution with the expected value of zero and the same variance (assumption 1),

$e_{t}$ are uncorrelated and have a finite variance (assumption 2).

Verifying these two assumptions one can determine the cause of a possible rejection of the null hypothesis: Is it heteroscedasticity of $e_{t}$ or rather autocorrelation?

Assuming that the assumption 1 is true and transforming the model (7), we have:

$$
r_{t}=\ln \left(\frac{s_{t}}{s_{t-1}}\right)=\mu+e_{t}
$$

This means that the continuously compound daily returns $r_{t}$ follow a normal distribution with expected value $\mu$ and variance equal $e_{t}$. Assuming also that individual rates of return are independent, the sample variance of $k$-period return is $k$ times the sample variance of one-period return. Thus, if $\mathrm{H}_{0}$ is true (i.e. prices are generated by a stochastic process given by the formula (7) and et satisfies assumption 1), then:

$$
\frac{\operatorname{var}\left(r_{k}\right)}{k \cdot \operatorname{var}\left(r_{1}\right)}=1
$$


where $r_{k}$ is a logarithmic return from $k$ days.

Therefore the test of the null hypothesis can be based on the quotient of the variance (see the left side of equation (9)). If $\mathrm{H}_{0}$ is true, the variance ratio calculated from the sample should be equal to unity.

The distribution of the test statistics (variance ratio):

$$
\mathrm{z}(\mathrm{k})=\frac{\mathrm{IW} \mathrm{k}-1}{\sqrt{\mathrm{L}(\mathrm{k})}}
$$

where:

$\bar{p}=\frac{1}{n k} \sum_{t=1}^{n k}\left(p_{t}-p_{t-1}\right)$,

$\overline{\operatorname{var}}\left(r_{1}\right)=\frac{1}{n k-1} \sum_{t=1}^{n k}\left(p_{t}-p_{t-1}-\bar{p}\right)^{2}$,

$\overline{\operatorname{var}}\left(r_{k}\right)=\frac{1}{(n k-k-1)(1-1 / n)} \sum_{t=k}^{n k}\left(p_{t}-p_{t-k}-k \bar{p}\right)^{2}$,

$I W(k)=\frac{\overline{\operatorname{var}}\left(r_{k}\right)}{k \cdot \overline{\operatorname{var}}\left(r_{1}\right)}$,

$L(k)=\frac{3 n k^{2}}{2(2 k-1)(k-1)}$,

follows standard normal distribution asymptotically (Lo and MacKinlay 1989).

Assuming the truth of the assumption 2, which is more realistic, the null hypothesis can be verified using the statistic:

$$
\mathrm{z}^{*}(\mathrm{k})=\frac{\mathrm{IW}_{\mathrm{k}}-1}{\sqrt{\mathrm{L}^{*}(\mathrm{k})}}
$$

where:

$$
\begin{aligned}
& L^{*}(k)=\sum_{j=1}^{k-1}\left[\left(\frac{2(k-j)}{k}\right)^{2} \cdot V(j)\right], \\
& V(j)=\frac{\sum_{t=j+1}^{n k}\left(p_{t}-p_{t-1}-\bar{p}\right)^{2} \cdot\left(p_{t-j}-p_{t-j-1}-\bar{p}\right)^{2}}{\left[\sum_{t=1}^{n k}\left(p_{t}-p_{t-1}-\bar{p}\right)^{2}\right]^{2}},
\end{aligned}
$$

It also follows standard normal distribution.

Statistics $z(k)$ and $z^{*}(k)$ allow to verify the null hypothesis, answering the question whether the equation (7) may model the analyzed prices, properly.

\section{Autocorrelation tests}

The autocorrelation test examines whether the data in the time series are correlated or not, portmanteau (Box-Pierce) and adjusted portmanteau (Box-Ljung) examine whether the price changes are independent random variables with identical distributions.

Autocorrelation test verifies the following null hypothesis:

$\mathrm{H}_{0}: \rho=0$ (returns are not correlated with each other)

against

$\mathrm{H}_{1}: \rho \neq 0$ ( rates of return are correlated). 
To verify the null hypothesis one can use the autocorrelation coefficient of returns given by the formula:

$$
\hat{\rho}(k)=\frac{\sum_{t=1}^{T-k}\left(R_{t}-\bar{R}_{T}\right)\left(R_{t+k}-\bar{R}_{T}\right)}{\sum_{t=1}^{T}\left(R_{t}-\bar{R}_{T}\right)^{2}},
$$

where:

$\hat{\rho}(k)$ is the autocorrelation of order $k$,

$\bar{R}_{T}$ is the mean return $\left(\bar{R}_{T}=\frac{1}{T} \sum_{t=1}^{T} R_{t}\right)$,

$T$ is the number of observations,

$R_{t}$ is the rate of return at time $t$,

$R_{t+k}$ is the rate of return of prices that are $k$ moments distant from each other.

Assuming the truth of the null hypothesis $\mathrm{H}_{0}$ : "the elements of the series are uncorrelated with each other", the statistic:

$$
S=\sqrt{T} \hat{\rho}(k)
$$

follows normal distribution with parameters $\mathrm{N}(0,1)$ (Taylor 1986). The null hypothesis is rejected at $5 \%$, when the absolute value of the statistic $S$ is greater than 1.96.

The aim of the Box-Pierce and Box-Ljung tests is to verify the following null hypothesis:

$\mathrm{H}_{0}: \rho_{1}=\rho_{2}=\ldots=\rho_{m}=0$ (rates of returns are uncorrelated)

against

$\mathrm{H}_{1}: \rho_{i} \neq 0, \mathrm{i}=\{1, \ldots, \mathrm{m}\}$ (rates of return are correlated).

This tests examine the significance of the subsequent correlation coefficients.

In the case of Box-Pierce test, the statistic is:

$$
Q_{m}=T \sum_{k=1}^{m} \hat{\rho}(k)^{2},
$$

and in the Box-Ljung test, it is:

$$
Q_{m}^{\prime}=T(T+2) \sum_{k=1}^{m} \frac{\hat{\rho}(k)^{2}}{T-k}
$$

where:

$\hat{\rho}(k)$ - autocorrelation coefficient of order $k$, for $k=1, \ldots, m$ (compare the formula 10), 
$T$ - the length of the time series,

$m \approx \ln (T)$ - maximum delay.

Statistics $Q\left(Q^{\prime}\right)$ consist of numerous autocorrelation coefficients, and follow the $\chi_{m}^{2}$ distribution, which is the chi-squared with $m$ degrees of freedom (Mills 1999). When the value of empirical statistic $Q$ exceeds the value of $\chi_{m}^{2}$ theoretical distribution, $\mathrm{H}_{0}$ can be rejected at the pre-specified significance level.

The formulas (13) and (14) show that the number of degrees of freedom $m$ is the number of autocorrelation coefficients, which are taken into account when calculating statistics $Q$ or $Q$ '. It should be noted that for small " $m$ " one may not detect significant higher order autocorrelation, whereas too big " $m$ " may reduce the power of the test due to the presence of insignificant higher-order autocorrelation.

\section{Data and preliminary analysis}

The data covers daily closing prices of crude oil in USD per barrel from January 4, 2000 to December 31, 2015 from the Bloomberg database (www.bloomberg.com) and includes, both West Texas Intermediate (WTI) and Brent quotations. They are displayed in Figures 1 and 2 together with their logarithmic returns. The West Texas Intermediate (USA origin) and Brent (North West Europe origin) crude oil prices are chosen to represent the oil market as they are key global marker crudes that are used as pricing benchmarks. During the period under consideration WTI traded between a low of $\$ 17.45$ (November 15, 2001) and a high of $\$ 145.29$ (July 3, 2008) per barrel, while Brent traded between a low of $\$ 17.68$ (November 15, 2001) and a high of $\$ 146.08$ (July 3, 2008) per barrel.

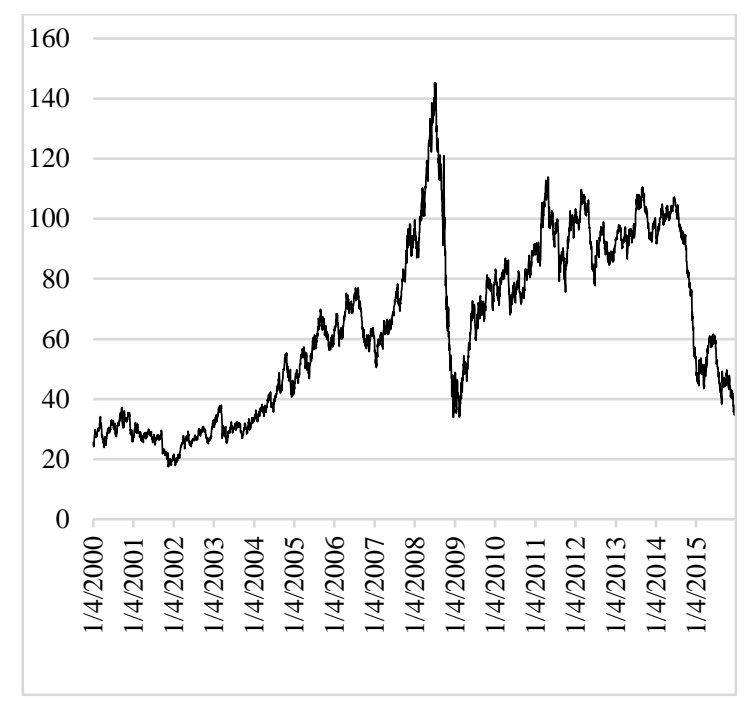




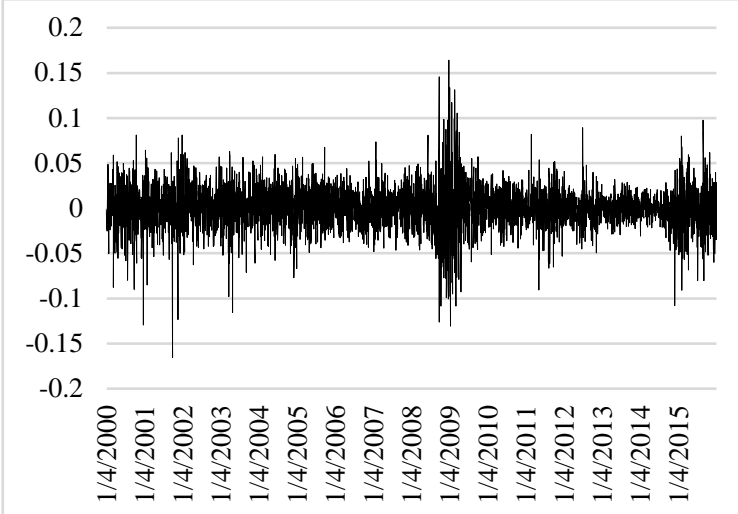

Fig. 1 . Daily WTI crude oil prices and logarithmic returns

Source: own elaboration.

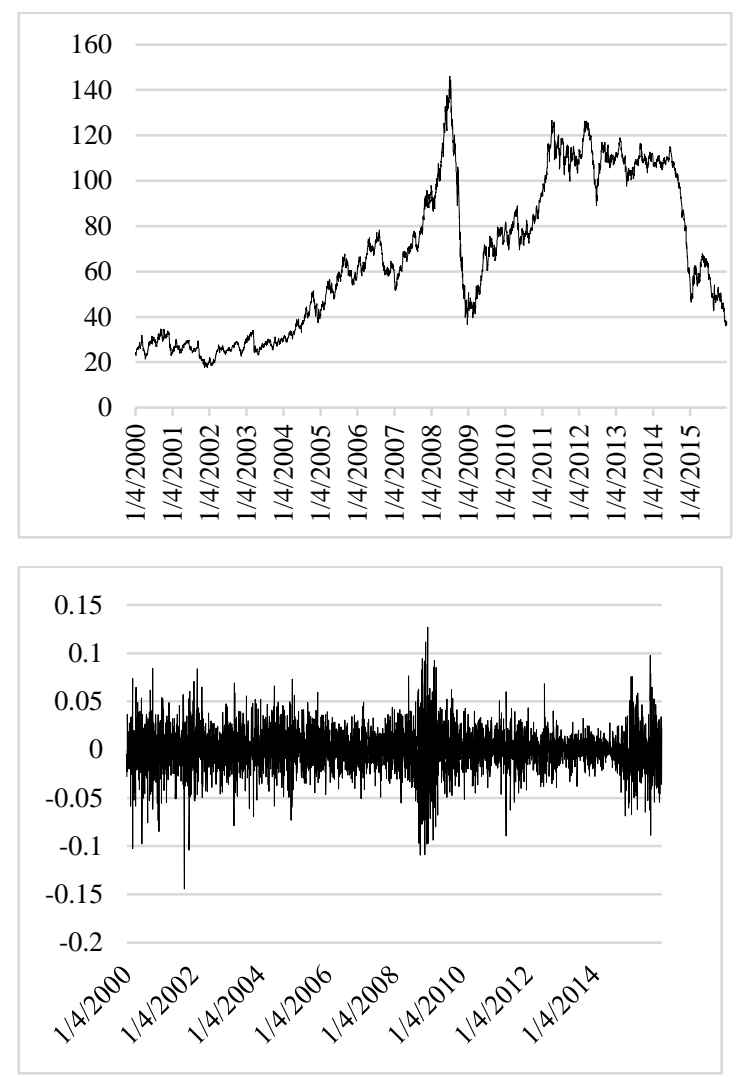

Fig. 2. Daily Brent crude oil prices and logarithmic returns

Source: own elaboration. 
In table 1, there are reported descriptive statistics of oil daily returns for evaluation period from January 2000 to December 2015 consisting of 4173 observations. Both, WTI and Brent are characterized by a daily mean close to zero and their volatilities do not differ remarkably. Additionally, they are described by negative skewness. Moreover, kurtosis is larger than 3. To follow, the Jarque-Bera statistic (JB) of normality confirms the rejection of null hypothesis for both return series at $5 \%$ level of significance. They are also characterized by strong linear correlation (Pearson correlation coefficient equals 0.86).

Table 1. Summary statistics for logarithmic returns of crude oil prices WTI and Brent in period January 2000 - December 2015

\begin{tabular}{|l|l|l|}
\hline Characteristics & WTI & Brent \\
\hline Number of observations & 4173 & 4173 \\
\hline Mean (\%) & 0.0089 & 0.0095 \\
\hline Standard deviation (\%) & 2.361 & 2.1658 \\
\hline Kurtosis & 4.496 & 3.130 \\
\hline Skewness & -0.176 & -0.191 \\
\hline Minimum (\%) & -16.545 & -14.437 \\
\hline Maximum (\%) & 16.410 & 12.707 \\
\hline JB & $3526.02^{*}$ & $1723.54^{*}$ \\
\hline Pearson correlation & 0.86 & \\
\hline
\end{tabular}

Source: own calculations $\quad{ }^{*}$ Rejection of null hypothesis of normality at 0.05

\section{Empirical results}

Runs test

Table 2 presents values of $K$ statistic (equation (3)), calculated for both WTI and Brent logarithmic returns. They show we cannot reject the null hypothesis at $5 \%$. Thus, we can expect $R_{t}^{*}$ to be generated by the white noise $(|K|<$ 1.96). In consequence, both WTI and Brent markets may be efficient in a weak-form. Additionally, positive values of $K$ suggest existence of trends in oil returns.

Table 2. Values of $K$ statistic for WTI and Brent returns

\begin{tabular}{|l|l|}
\hline Crude oil & K \\
\hline WTI & 1.86666 \\
\hline Brent & 1.90793 \\
\hline
\end{tabular}

Source: own calculations.

Variance ratio test

Results of variance ratio test are reported in table 3 (the tests were performed for logarithmic returns from 1 up to 10 days $(k=1, \ldots, 10))$. All $z(k)$ statistics, given in table 3 , are not significant at $5 \%$. Thus, the null hypothesis cannot be rejected and oil prices may be generated by the stochastic process fulfilling assumption (1). Moreover, model (7), fulfilling assumption 2 is a good approximation of analyzed oil prices (with exception of $k=3$ for WTI and $k>4$ for Brent). Additionally, values of all variance ratios (IW) are smaller than 1 and decrease when $k$ increases. Thus, the logarithmic returns under consideration are characterized by negative coefficients of autocorrelation (compare table 4).

Table 3. Results of the variance ratio test for logarithms of oil prices

\begin{tabular}{|l|l|l|l|l|l|l|l|l|l|l|}
\hline & $\mathrm{k}$ & 2 & 3 & 4 & 5 & 6 & 7 & 8 & 9 & 10 \\
\hline \multirow{2}{*}{ WTI } & $\mathrm{IW}(\mathrm{k})$ & 0.96501 & 0.93249 & 0.92890 & 0.93519 & 0.92550 & 0.91320 & 0.90215 & 0.89036 & 0.87661 \\
\cline { 2 - 10 } & $\mathrm{z}(\mathrm{k})$ & -0.00001 & -0.00005 & -0.00006 & -0.00008 & -0.00011 & -0.00015 & -0.00020 & -0.00025 & -0.00032 \\
\hline
\end{tabular}




\begin{tabular}{|l|l|l|l|l|l|l|l|l|l|l|} 
& $z^{*}(\mathrm{k})$ & -1.56181 & $-2.00937^{*}$ & -1.68244 & -1.30853 & -1.33062 & -1.40513 & -1.45970 & -1.52494 & -1.90063 \\
\hline \multirow{4}{*}{ Brent } & $\mathrm{IW}(\mathrm{k})$ & 0.94397 & 0.92310 & 0.92201 & 0.93561 & 0.92880 & 0.92756 & 0.92449 & 0.92404 & 0.91718 \\
\cline { 2 - 10 } & $\mathrm{z}(\mathrm{k})$ & -0.00002 & -0.00005 & -0.00007 & -0.00008 & -0.00010 & -0.00013 & -0.00015 & -0.00017 & -0.00021 \\
\cline { 2 - 10 } & $Z^{*}(\mathrm{k})$ & $-2.72339^{*}$ & $-2.49240^{*}$ & $-1.99876^{*}$ & -1.40154 & -1.36683 & -1.25628 & -1.20415 & -1.12757 & -1.34868 \\
\hline
\end{tabular}

Source: own calculations

${ }^{*}$ Significance at 0.05

Autocorrelation test

Table 4 presents results of the autocorrelation test for logarithmic returns, where autocorrelations of order $k=1,2, \ldots, 10$ are verified.

Table 4. Values of autocorrelation of order $k$ (rho) and $S$ stastistics

\begin{tabular}{|c|c|c|c|}
\hline$k$ & & WTI & Brent \\
\hline \multirow{2}{*}{1} & rho(1) & -0.036 & -0.057 \\
\hline & S & $-2.318^{*}$ & $-3.657^{*}$ \\
\hline \multirow{2}{*}{2} & rho(2) & -0.031 & -0.003 \\
\hline & $S$ & $-2.016^{*}$ & -0.191 \\
\hline \multirow{2}{*}{3} & rho(3) & 0.025 & 0.018 \\
\hline & $S$ & 1.606 & 1.188 \\
\hline \multirow{2}{*}{4} & rho(4) & 0.021 & 0.036 \\
\hline & S & 1.370 & $2.323^{*}$ \\
\hline \multirow{2}{*}{5} & rho(5) & -0.042 & -0.049 \\
\hline & $S$ & $-2.735^{\star}$ & $-3.162^{*}$ \\
\hline \multirow{2}{*}{6} & rho(6) & -0.020 & 0.011 \\
\hline & $S$ & -1.269 & 0.740 \\
\hline \multirow{2}{*}{7} & rho(7) & -0.007 & -0.009 \\
\hline & $S$ & -0.481 & -0.569 \\
\hline \multirow{2}{*}{8} & rho(8) & -0.014 & 0.008 \\
\hline & $S$ & -0.889 & 0.529 \\
\hline \multirow{2}{*}{9} & rho(9) & -0.020 & -0.033 \\
\hline & $S$ & -1.321 & $-2.127^{*}$ \\
\hline \multirow{2}{*}{10} & rho(10) & 0.010 & 0.042 \\
\hline & $S$ & 0.669 & 2.685 \\
\hline
\end{tabular}

Source: own calculations $\quad{ }^{*}$ Significance at 0.05

Results, given in table 4, suggest rejection of the null hypothesis $\mathrm{H}_{0}$ : „oil prices are independent random variables” for both, WTI and Brent in the case of autocorrelation of orders $k=1$ and $k=5(|\sqrt{T} \hat{\rho}(k)|>1.96)$. On the contrary, we cannot reject the null hypothesis for both of them in the case of autocorrelation of order $k=\{3,6,7,8\}$. Evidence for other orders of autocorrelation is mixed. Although in most cases the null hypothesis cannot be rejected, values of coefficient of correlation $\hat{\rho}(k)$ differ from zero. However, their moduli are small. Thus, we expect oil prices to be autocorrelated, but their autocorrelations are too weak to let us draw definite conclusions.

Box-Pierce and Box-Ljung tests 
Results of Box-Pierce and Box-Ljung tests, that have been performed on logarithmic returns, are given in table 5. There are considered different numbers of lags $(m): 10,20$ and 30. Empirical values of $Q_{m}$ and $Q_{m}^{\prime}$ statistics are compared to the theoretical values of chi-squared distribution: $18.31,31.41$ and 43.77 respectively.

Table 5. Values of $Q$ and $Q$ ' statistics

\begin{tabular}{|l|l|l|l|}
\hline Item & $\mathrm{m}$ & Qm & Q'm \\
\hline \multirow{4}{*}{ WTI } & 10 & 26.197 & 26.210 \\
\cline { 2 - 4 } & 20 & 43.000 & 43.068 \\
\cline { 2 - 4 } & 30 & 52.362 & 52.480 \\
\hline \multirow{4}{*}{ Brent } & 10 & 43.098 & 43.128 \\
\cline { 2 - 4 } & 20 & 62.926 & 63.017 \\
\cline { 2 - 4 } & 30 & 80.380 & 80.563 \\
\hline
\end{tabular}

Source: own calculations

Results in table 5 suggest rejection of the null hypothesis regardless the number of lags. All values of $Q_{m}$ and $Q_{m}^{\prime}$ statistics are greater than respective theoretical values of chi-squared distribution. This lets us state that returns are correlated. Again, the correlations are too weak to draw definite conclusions.

\section{Concluding remarks}

According to Chai et.al. (2011), oil is an indispensable energy product, chemical raw material, and also a strategic material that plays an irreplaceable role in national defense. Nowadays, many countries' economies critically rely on oil consumption, so frequent and dramatic volatility of the world oil price affects the world economy, governments, and energy industry. What is more, the volatility of oil price not only impacts on the economic growth, but also directly influences energy enterprises and investors. That is why it is important to examine behavior of oil markets.

This paper has explored weak-form efficiency in the WTI and Brent crude oil markets from 2000 through 2015 using few statistical tests: the runs test, the variance ratio test, the autocorrelation tests. Their results, however, do not provide clear answers to the question whether oil markets are efficient in a weak-form (although the runs test and the variance ratio test show that time-series of WTI and Brent prices are well described by the random walk). This opens a door to further investigations with the use of alternative methodology.

\section{References}

[1] Aatola, P., Ollikka, K., Ollikainen, M. (2010). Weak and Semi-strong Forms of Informational Efficiency in the EU ETS Markets. University of Helsinki Discussion Papers, 48, ww.helsinki.fi.

[2] Bachelier, L. (1900), Théorie de la spéculation (PDF), Annales Scientifiques de l'École Normale Supérieure, 3 (17), pp. 21-86.

[3] Borges, M. (2010). Efficient Market Hypothesis in European Stock Markets. European Journal of Finance, 16(7), $711-726$.

[4] Chai, J., Guo, J.E., Meng, L., Wang, S.Y. (2011). Exploring The Core Factors and Its Dynamic Effects on Oil Price: An Application on Path Analysis and BVAR-TVP Model. Energy Policy, 39, 8028-8036.

[5] Charles, A., Darne, O. (2009). The Efficiency of the Crude Oil Market: Evidence from Variance Ratio Tests. Energy Policy, 37, 4267-4272.

[6] Cowles, A. (1933). Can Stock Market Forecasters Forecast? Econometrica, 1: 309-324.

[7] Czekaj, J., Woś, M., Żarnowski, J. (2001). Efektywność giełdowego rynku akcji w Polsce. Z perspektywy dziesięciolecia. Wydawnictwo Naukowe PWN, Warszawa.

[8] Domański, Cz., Pruska, K. (2000). Non-classical Statistical Methods. Warsaw: WN PWN (in Polish).

[9] Fama, E.F. (1970). Efficient Capital Markets: A Review of Theory and Empirical Work. Journal of Finance, 25, 383417. 
[10] Fama, E.F., French, K.R. (1988). Permanent and Temporary Components of Stock Prices. Journal of Political Economy, 96, 246-273.

[11] Fama, E.F. (1991). Efficient Capital Markets: II. Journal of Finance, 46, 1575-1617.

[12] Fama, E.F. (1998). Market Efficiency, Long-term Returns, and Behavioral Finance. Journal of Financial Economics, 49, 283-306.

[13] Górska, A., Krawiec, M. (2013). The Analysis of Weak-form Efficiency in the Market of Precious Metals. Zeszyty Naukowe Uniwersytetu Szczecińskiego: Finanse, Rynki Finansowe, Ubezpieczenia, 768 (63), 143-156 (in Polish).

[14] Górska, A., Krawiec, M. (2015). Calendar Effects in the Market of Crude Oil. Scientific Journal of Warsaw University of Life Sciences - SGGW: Problems of World Agriculture 2015, 15 (30), 4, $62-70$.

[15] Guidi, F., Gupta, R., Maheshwari, R. (2011). Weak-form Market Efficiency and Calendar Anomalies for Eastern Europe Equity Markets. Journal of Emerging Market Finance, 10(3), 337-389.

[16] Haugen, R.A. (1996). Modern investment theory. Prentice Hall, Upper Saddle River, NJ.

[17] Khrapko, V. (2013). Testing the Weak-form Efficiency Hypothesis in the Ukrainian Stock Market Versus Those of the USA, Russia, and Poland. Ekonomika, 92(2), 108-121.

[18] Lo, A.W., MacKinlay, A.C. (1988). Stock Market Prices Do Not Follow Random Walk: Evidence From a Simple Specification Test. Review of Financial Studies, 1, 41-66.

[19] Lo, A., MacKinlay, A.C. (1989). The Size and Power of the Variance Ratio Test in Finite Samples: a Monte Carlo Investigation. Journal of Econometrics, 40, 203-238.

[20] Lo, A., MacKinlay, A.C. (1998). Stock Market Prices Do Not Follow Random Walks: Evidence From a Simple Specification Tests. Review of Financial Studies, 1(1), 41-66.

[21] Mills, T. (1999). The Econometric Modelling of Financial Time Series. Cambridge: Cambridge University Press.

[22] Nisar, S., Hanif, M. (2012). Testing Weak-form of Efficient Market Hypothesis: Empirical Evidence from South Asia. World Applied Sciences Journal, 17(4), 414-427.

[23] Ntim, C.G., English, J., Nwachukwu, J., Wang, Y. (2015). On the Efficiency of the Global Gold Markets. International Review of Financial Analysis, 41, 218-236.

[24] Popescu, M.F. (2016). The Volatility of Oil Prices on Stock Exchanges in the Context of Recent Events. Studies in Business and Economics 11(1), 112-123.

[25] Samuelson, P. (1965). Proof that Properly Anticipated Prices Fluctuate Randomly, Industrial Management Review, Spring 6, 41-49.

[26] Shaker, A.T.M. (2013). Testing the Weak-form Efficiency of the Finnish and Swedish Stock Markets. European Journal of Business and Social Sciences, 2(9), 176-185.

[27] Smith, G. (2002) Tests of the Random Walk Hypothesis for London Gold Prices. Applied

[28] Economic Letters, 9 (10), 671-674.

[29] Taylor, S. J. (1986). Modeling Financial Time Series. New York, NY: John Wiley and Sons. 